\title{
Alterations in Levels of Oxidative Stress Biomarkers, Some Serum Interleukins and Hormones in Infertile Women
}

\author{
Sundus Majeed Hamza ${ }^{1}$ \\ Sahib Jumaa Abd-alrahman ${ }^{2}$ \\ ${ }^{1}$ Biology Department, Garmian University, Kalar, KRG/ Iraq \\ ${ }^{2}$ Biology Department, Karkuk University, Karkuk, Iraq
}

\begin{abstract}
The aim of this study was to evaluate the effect of oxidative stress and some serum interleukins and hormones levels of women with primary infertility, and to reveal the correlation between them.

A total of 120 infertile women with different etiologies and 45 fertile women as a control were investigated, their age ranged between (16-45) years old. The levels of serum TAC, SOD activity, GSH, MDA, Mg, Zn, catalase activity, interleukin$1 \beta$ and interleukin- 8 were estimated, also the levels of LH, FSH, prolactin, progesterone, $\mathrm{AMH}$, inhibin B and leptin were estimated.

The current results were revealed that there was a significant elevation in the levels of MDA, interleukin- $1 \beta$, prolactin and leptin, and a significant decrease in TAC, SOD, GSH, Mg, Zn, catalase activity, $\mathrm{AMH}$ and inhibin B between the infertile and fertile groups. There was a positive correlation between SOD with $\mathrm{AMH}$, inhibin B and $\mathrm{Mg}$, and positive correlation between LH and FSH, TAC and inhibin B. there was a negative correlation between FSH and inhibin B. In conclusion, it suggested that inhibin B may play a role in the antioxidant-oxidant balance.
\end{abstract}

KeyWords: Infertility, Antioxidants, Interleukin, Antimularian hormone, Leptin 


\section{Introduction}

The miracle of life's possibility is gained by a healthy reproductive system. The female reproductive organs play a role in the reproductive process, which includes: menstrual cycle, conception, pregnancy and delivery (Noori, 2012). Female infertility may be caused by age, physical problems, hormone abnormalities, and lifestyle or environmental factors. Most problems deal with producing eggs, the ovaries may stop functioning before natural menopause or may not release eggs regularly or they may not release a healthy one (Olooto et al., 2012a). Stress plays an integral role in the pathogenesis of infertility resulting from increased free radical generation and/or decreased levels of scavenging antioxidants (D'Hooghe and Debrock, 2002).

Antioxidants are a family of vitamins, minerals and other nutrients that help to protect the body from the oxidative damage. They work as a defense system. Glutathione is present inside and outside the cells in human body and its effects on oocyte and embryo quality. Follicular fluid GSH is found in high concentrations of different sized follicles; and may act as an antioxidant to protect oocytes from free radicals during oocyte growth and maturation (Liu et al., 2002). Peritoneal fluid from patients with endometriosis has been shown to exhibit inadequate antioxidant defenses, including low total antioxidant capacity (TAC) and significantly reduced levels of individual antioxidant enzymes such as superoxide dismutase (SOD) (Lambrinoudaki et al., 2009). Catalase enzyme has a major role in the first defense line of enzymatic antioxidant and very important enzyme 
in reproductive reactions, despite catalase enzyme is distributed over the cell, it concentrates in peroxisomes and mitochondria (Franks et al., 2008). Malondialdehyde (MDA) is an endogenous product of enzymatic and free radicals -induced lipid peroxidation (Niedernhofer et al., 2008). Therefore, MDA levels measurement can be widely used as an important indicator of oxidative stress and lipid peroxidation (Jetawattana, 2005). Catalase activity level was significantly decreased whereas MDA levels were significantly increased in females with primary infertility when compared with those of the fertile group (Hussain et al., 2013).

Zinc works as antioxidants in egg production and hormone regulation such as estrogen, progesterone and testosterone levels throughout the menstrual cycle (Rajeswari and Swaminathan, 2015). Magnesium is also essential for reducing complications of female reproductive system (DeRidder and Gossen, 1988), because it is essential for sex hormone production and function (Fukai and Murayama, 1984).

Interleukins as a group of cytokines are important for reproductive processes and work as immunoregulatory molecules responsible for modulating several biological responses including the ovarian function (Calogero et al., 1998 and Mahdi, 2011).

Hormone abnormalities had been evaluated in infertile women; infertile women with a proper menstrual cycle had higher level of follicle-stimulating hormone (FSH) and luteinizing hormone (LH). The incidence of high prolactin levels with low levels of LH, FSH and progesterone may cause anovulation and hence infertility, due to the important role of $\mathrm{LH}$ and $\mathrm{FSH}$ in graffian follicle formation and 
estrogen production (Olooto et al., 2012b).

Anti-Mullerian hormone $(\mathrm{AMH})$ is mainly secreted by the granulosa cells of primary, pre-antral, and small antral follicles, suggesting an important role of $A M H$ in steriodogenesis and folliculogenesis. (Saleh et al., 2015). Inhibin B is the primary regulator of FSH secretion during the follicular phase. The decrease in inhibin B levels lifts the inhibitory tone over the hypothalamicpituitary- ovarian axis allowing FSH levels to increase and estradiol decrease (Vander, 2001). Leptin has an effect on the ovary and the hypothalamus, high level of leptin decrease estradiol production in the ovary, and leptin receptors are also located in the hypothalamus regulate $\mathrm{GnRH}$, therefore leptin induces GnRH secretion (Jungheim, 2015).

\section{Materials and Methods}

\section{A. Subjects and Samples}

We investigated 120 infertile women and 45 fertile women as control, with age ranging between 18-45 years old, who attended the Sheray Naqeeb hospital in Kalar city from December 2014 to February 2015. The exclusion criteria include none of the women had previous ovarian surgery, no contraceptive methods, no receiving sex steroids or any drug known to affect ovarian function for at least 2 months, and all of them with primary infertility, They were subdivided into three groups according to the age, as following: Group 1: 55 women aged between 16-25 years, 40 of them infertile and 15 were fertile. Group 2: 55 women aged between 26-35 years, 40 of them infertile 
and 15 were fertile. Group 3: 55 women aged between 36-45 years, 40 of them infertile and 15 were fertile. Venous blood had been collected from each woman after 24 hours of menstrual cycle, and the sera were separated by centrifuge at $3000 \mathrm{rpm}$ for 10 minutes; the samples were stored at $(-30){ }^{\circ} \mathrm{C}$ in deep freezer.

\section{B. Biochemical Assays}

\section{Estimation of Antioxidants}

SOD activity is estimated by using SOD Assay Kit-WST (Dojindo, Japan). SOD Activity was measured by inhibiting the reduction of nitroblue tetrazolium to produces a water-soluble formazan dye with the superoxide anion using microplate reader (StateFax, USA) at $450 \mathrm{~nm}$. TAC concentration was estimated by using TAC Fast Track (LDN, Germany). This assay is based on the reaction of peroxides with peroxidase and the reaction of tetramethylbenzidine. Reduced glutathione (GSH) in the serum was estimated according to the method of Moron et al., the reaction of GSH with 5,5-dithio-bis (2 -nitrobenzoic acid) [DTNB] gives an yellow colored compound that absorbs spectrophotometrically at wavelength of $412 \mathrm{~nm}$. The analysis of MDA by 2-thiobarbituric acid assay has been employed in this study for the assessment of lipid peroxidation, and read the absorbance at $532 \mathrm{~nm} 9$ Wallace and Kelsey, 2010). Catalase enzyme activity was measured following the method of L. goth (Goth, 1991). The activity was determined spectrophotometrically by measuring the decrease in $\mathrm{H}_{2} \mathrm{O}_{2}$ absorbance at $240 \mathrm{~nm}$. The inductively coupled plasma optical emission spectroscopy (ICP-OES) (Spectro Arcos, Germany) used for analysis of $\mathrm{Mg}$ and $\mathrm{Zn}$. 


\section{Estimation of IL- $1 \beta$ and IL-8}

The kits provided by (KOMA BIOTECH, Korea), they are a quantitative kits, and use Sandwich-ELISA assay. The optical density (OD) is measured using microplate reader (Dynex, USA) at $450 \mathrm{~nm}$.

\section{Estimation of Hormones}

LH, FSH, prolactin, and progesterone assays were achieved by electrochemiluminescence immunoassay (Roche-Hitachi Cobas e 411) using quantitative kits (Cobas, Japan). The kits of AMH and inhibin B (MyBioSource, USA) and leptin (LDN, Germany) were use sandwich-ELISA assay and read the optical density (OD) by using microplate reader (Dynex, USA) at $450 \mathrm{~nm}$.

\section{Statistical Analysis}

Duncan Post Hoc test was used to detect any possible correlation between the variables screened. Significant results were accepted at $\mathrm{P} \leq 0.05$.

\section{Results}

In the current study, the data was obtained demonstrated a significant decreasing in each of TAC and SOD activity, catalase activity and GSH levels, The data presents verified TAC means \pm SD at $(\mathrm{p}<0.05)$ in infertile and fertile groups were (1.30 \pm 0.36 and $1.91 \pm 0.30)$, SOD activity were (4.03 \pm 2.59 and $9.46 \pm 2.01)$, catalase activity $(4.33 \pm 2.15$ and $6.98 \pm 4.81)$ and GSH level $(0.41 \pm 0.26$ and $0.59 \pm$ 0.23 ) in respective, for more illustrations see Figure (1).

The results demonstrate a significant increase in MDA level in infertile group 
as compared with fertile group (4.23 \pm 1.79 and $2.02 \pm 0.91)$.

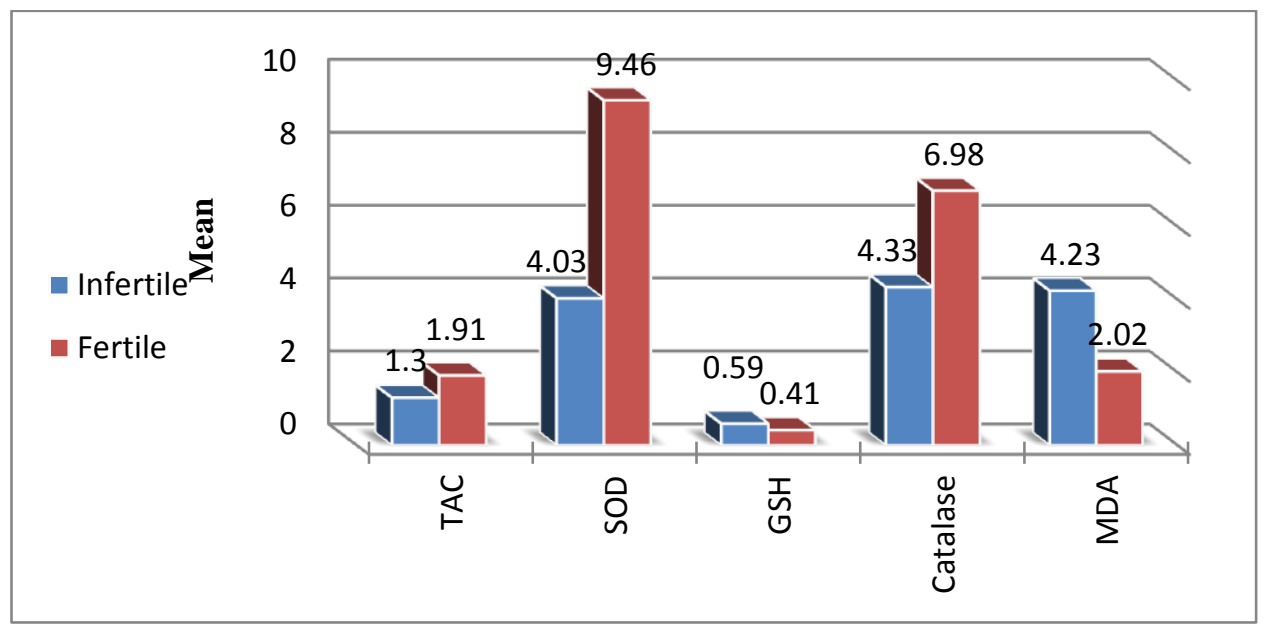

Figure (1): Levels of antioxidants in infertile and fertile groups

According to the data, it demonstrate that $\mathrm{Mg}$ and $\mathrm{Zn}$ were decreased significantly in infertile group as compared with the fertile group, the values of $\mathrm{Mg}$ in infertile and fertile groups were (20.59 3.18 and $23.90 \pm 2.84)$ and $\mathrm{Zn}$ were $(0.46 \pm 0.19$ and0.76 \pm 0.21$)$, as in Figure (2).

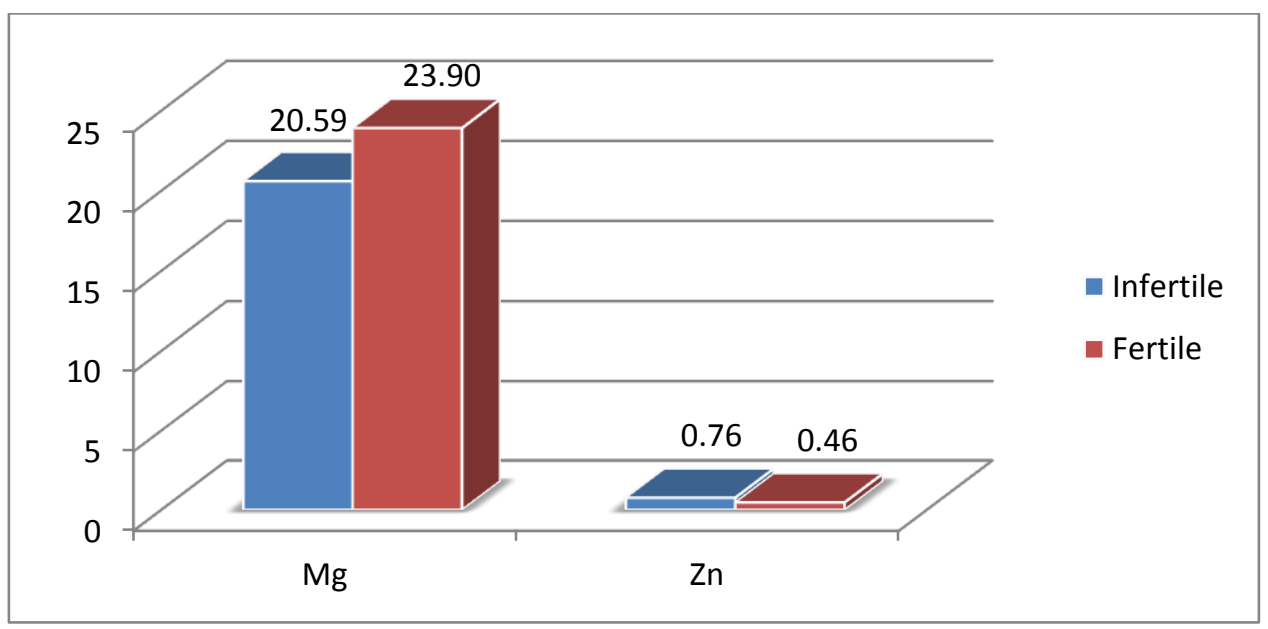

Figure (2): Levels of magnesium and zinc in infertile and fertile groups

The present data shows a significant elevation in the level of serum IL-1 $\beta$ between infertile (3.05 \pm 0.73$)$ and fertile group $(2.03 \pm 0.53)$, but IL-8 level was not 
significant higher in infertile group (35.00 \pm 5.95$)$ as compared with fertile group (24.65 \pm 3.27$)$; as shows in Figure (3).

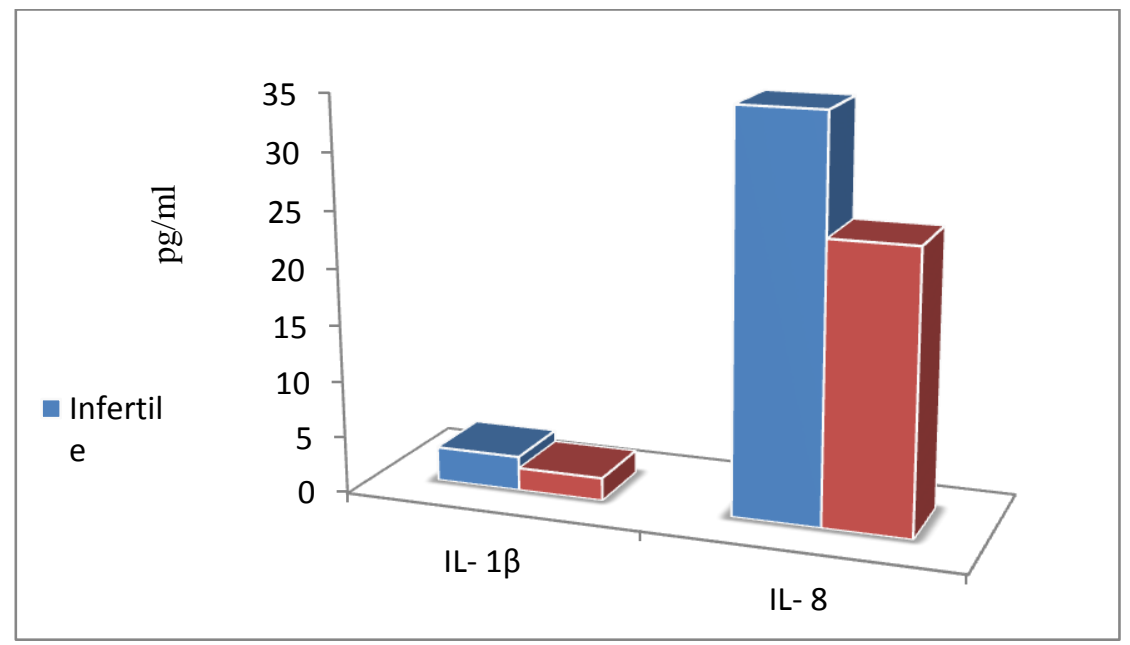

Figure (3): Levels of serum IL-1 $\beta$ and IL-8 in infertile and fertile groups

Our results shown in Figure (4) revealed that the levels of LH and FSH were not significant increased, while there was significant increase in prolactin levels of infertile group $(27.98 \pm 4.33)$ when compared with fertile group $(10.09 \pm 2.51)$.

According to the results that were shown in Figure (5), the level of progesterone was non- significantly elevated in infertile group comparing to fertile group, while the level of $\mathrm{AMH}$ was significantly decreased in infertile group $(0.75 \pm 0.20)$ comparing to fertile group (1.19 \pm 0.18$)$. As well as the level of inhibin B was significantly decreased in infertile group (39.95 \pm 6.45$)$ comparing to fertile group (73.32 \pm 7.19$)$. While, the level of leptin was significantly increased in infertile group (28.98 \pm 4.25$)$ as compared to fertile group (24.58 \pm 3.89$)$, as shown in Figure (6).

In addition, the results show regarding to age groups a significant and not significant variations among the three age groups of infertile women, for more clarification see table (1). 


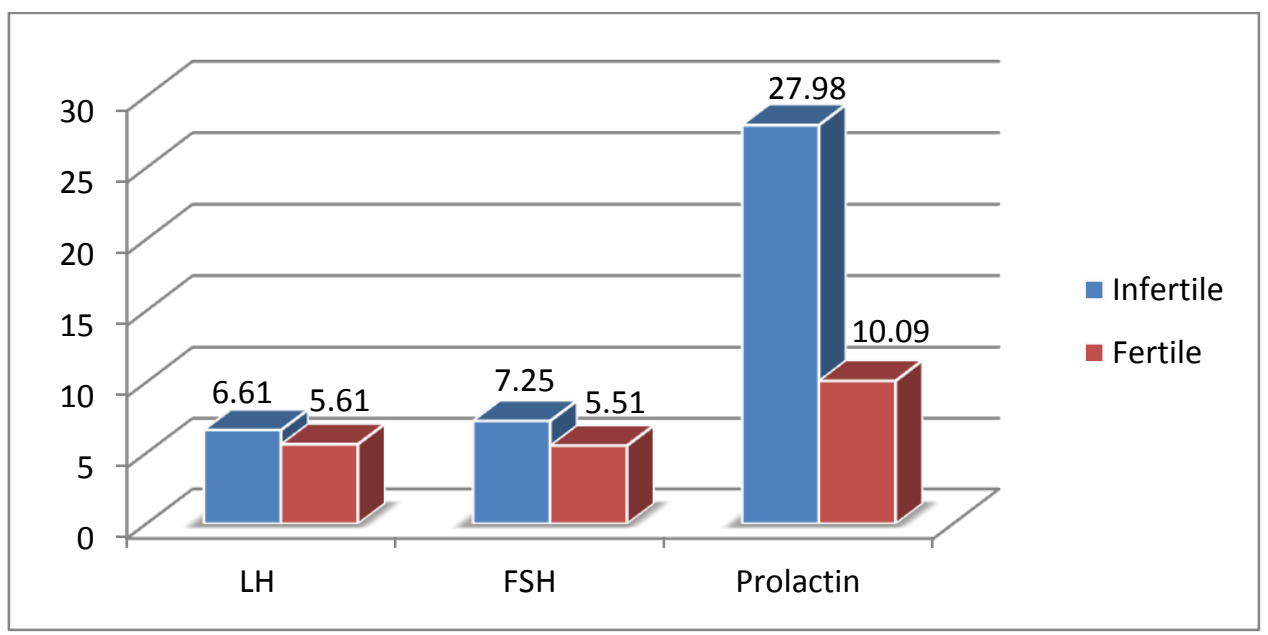

Figure (4): Levels of LH, FSH and prolactin in infertile and fertile groups

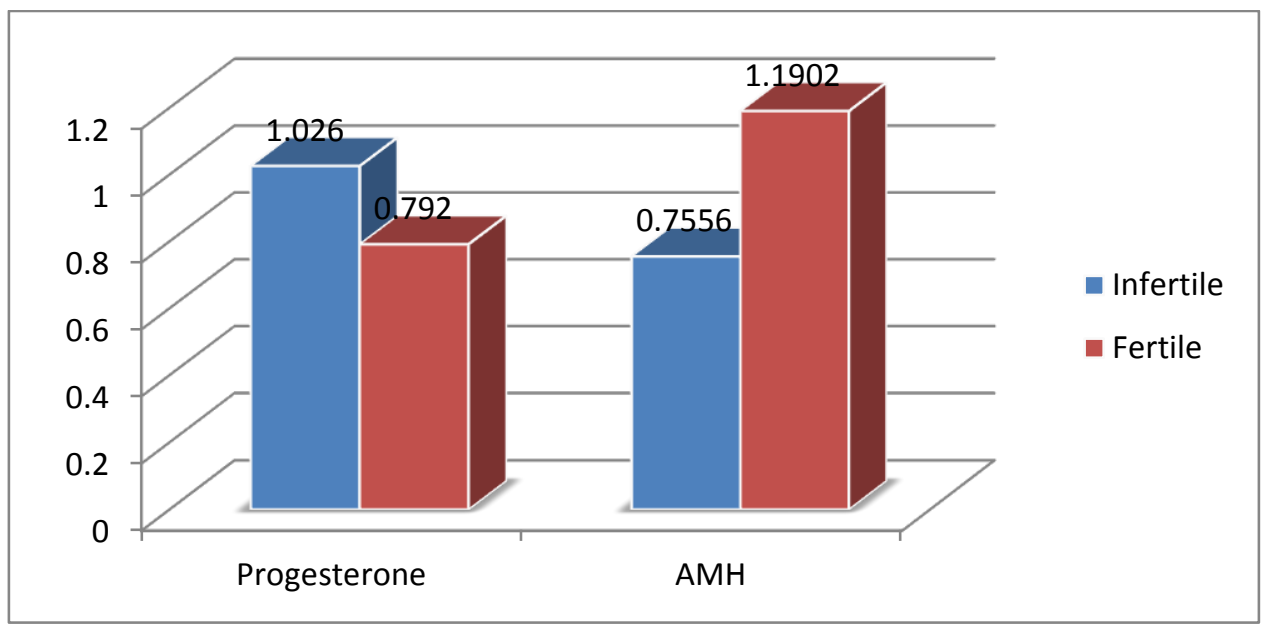

Figure (5): Levels of progesterone and AMH in infertile and fertile groups

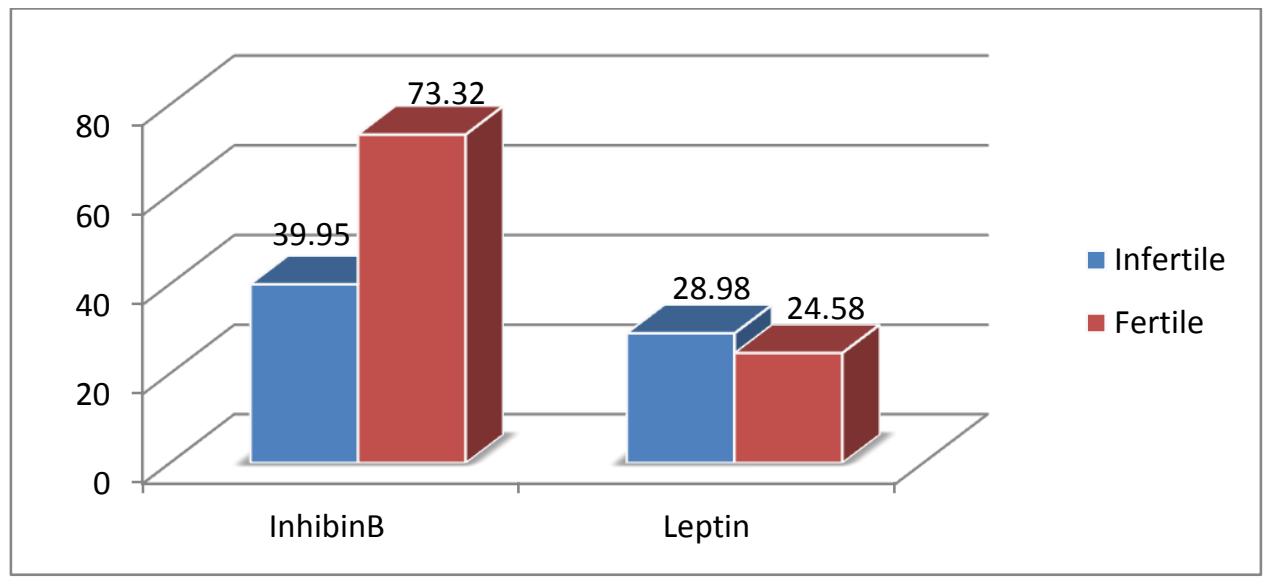

Figure (6): Levels of inhibin B and leptin in infertile and fertile groups 
Table (1): The levels of studied variables in relation to age groups

\begin{tabular}{|c|c|c|c|}
\hline Variables $\quad$ Age group & Group $1 \mathrm{n}=40$ & Group $2 \mathrm{n}=40$ & Group $3 n=40$ \\
\hline TAC (mmol/L) & $1.32 \pm 0.34 \mathbf{a}$ & $1.35 \pm 0.33 \mathbf{a}$ & $1.22 \pm 0.40 \mathbf{a}$ \\
\hline SOD $(\mathrm{mIU} / \mathrm{ml})$ & $3.44 \pm 1.14 \mathbf{a}$ & $4.95 \pm 0.92 \mathbf{a}$ & $3.69 \pm 0.46 \mathbf{a}$ \\
\hline MDA $(\mu \mathrm{mol} / \mathrm{L})$ & $3.82 \pm 1.01 \mathbf{a}$ & $3.82 \pm 1.11 \mathbf{a}$ & $4.51 \pm 1.05 \mathbf{a}$ \\
\hline Catalase (IU/ml) & $4.60 \pm 1.22 \mathbf{a}$ & $4.83 \pm 0.25 \mathbf{a}$ & $3.57 \pm 0.79 \mathbf{b}$ \\
\hline GSH $(\mathrm{mMolar} / \mathrm{L})$ & $0.45 \pm 0.21 \mathbf{a}$ & $0.45 \pm 0.10 \mathbf{a}$ & $0.33 \pm 0.08 \mathbf{a}$ \\
\hline $\mathbf{M g}(\mathrm{mg} / \mathrm{L}$ & $20.35 \pm 2.40 \mathbf{a}$ & $20.49 \pm 3.07 \mathbf{a}$ & $20.92 \pm 3.94 \mathbf{b}$ \\
\hline $\mathbf{Z n}(\mathrm{mg} / \mathrm{L})$ & $0.46 \pm 0.11 \mathbf{a}$ & $0.30 \pm 0.08 \mathbf{a}$ & $0.61 \pm 0.20 \mathbf{a}$ \\
\hline IL-1及 (pg/ml) & $2.30 \pm 0.74 \mathbf{b}$ & $2.72 \pm 0.80 \mathbf{b}$ & $4.15 \pm 1.15 \mathbf{a}$ \\
\hline IL-8（pg/ml) & $28.83 \pm 3.43 \mathbf{b}$ & $47.31 \pm 6.03 \mathbf{a}$ & $28.88 \pm 5.69 \mathbf{b}$ \\
\hline $\mathbf{L H}(\mathrm{mIU} / \mathrm{ml})$ & $4.99 \pm 0.84 \mathbf{b}$ & $6.32 \pm 1.72 \mathbf{b}$ & $8.52 \pm 1.99 \mathbf{a}$ \\
\hline FSH (mIU/ml) & $5.94 \pm 1.74 \mathbf{b}$ & $6.21 \pm 2.59 \mathbf{b}$ & $9.60 \pm 1.76 \mathbf{a}$ \\
\hline Prolactin (ng/ml) & $25.53 \pm 4.17 \quad \mathbf{b}$ & $41.20 \pm 8.16 \mathbf{a}$ & $17.23 \pm 3.75 \mathbf{b}$ \\
\hline Progesterone $(\mathrm{pg} / \mathrm{ml})$ & $1.12 \pm 0.36 \mathbf{a}$ & $1.36 \pm 0.33 \mathbf{a}$ & $0.58 \pm 0.18 \mathbf{b}$ \\
\hline $\mathbf{A M H}(\mathrm{ng} / \mathrm{ml})$ & $0.89 \pm 0.19 \mathbf{a}$ & $0.78 \pm 0.63 \mathbf{a}$ & $0.58 \pm 0.31 \mathbf{a}$ \\
\hline Inhibin B (pg/ml) & $47.50 \pm 6.89 \mathbf{a}$ & $37.80 \pm 6.34 \mathbf{a}$ & $34.53 \pm 4.01 \mathbf{a}$ \\
\hline Leptin (ng/ml) & $27.81 \pm 4.80 \mathbf{a}$ & $27.09 \pm 3.68 \mathbf{a}$ & $32.05 \pm 2.97 \mathbf{a}$ \\
\hline
\end{tabular}

In this study, the Pearson correlation was used to investigate the relationships between the variables of all values. There was a positive correlation between LH and FSH $(r=0.578)$, TAC and inhibin B $(r=0.368)$, SOD and AMH $(r=231)$, SOD and inhibin $\mathrm{B}$ ( $\mathrm{r}=0.364)$, SOD and $\mathrm{Mg}(\mathrm{r}=0.461)$. A negative correlation also found between FSH and inhibin B ( $\mathrm{r}=-0.442)$.

\section{Discussion}

The physiological role of ROS during ovulation and regulation of ovarian mesenchyme growth (Farzadi et al., 2013), increased ROS causes oxidative stress 
which is involved in numerous pathological conditions of female infertility (Gupta et al., 2009).

These hormonal imbalances of (LH, FSH and prolactin) have an impact on ovulation and menstruation because FSH and $\mathrm{LH}$ are needed for follicular maturation at the beginning of the monthly cycle, hence LH stimulates theca cells to produce estrogens and FSH stimulates recruitment of secondary ovarian follicles and the secretion of estradiol from granulosa cells (Boehm et al., 2015). The current study revealed that AMH has decreased significantly with infertility, generally this result goes along with a study on PCOS patients, which revealed the multiple follicles produce large amounts of estradiol that inhibits FSH release thereby preventing further follicular development. AMH may be involved in regulating the progression of follicles into growth phase, and abnormalities in AMH have also been proposed as contributors to the etiology of PCOS (Franks et al., 2008).

The current data appeared a significant decreased in inhibin B levels between infertile and fertile groups; it also appeared decreasing in inhibin B corresponding with age. This result confirmed by other study concluded that serum concentrations of inhibin B decrease with age and premature ovarian failure; thus, inhibin B has largely been considered a marker of ovarian activity, rather than ovarian reserve (Domingues et al., 2010). This diagnostic test can detect a decrease in AMH levels five years before a difference in the levels of FSH or inhibin B is noticed (Zheng et al., 2008).

The results of current study showed significant differences in TAC levels between infertile and fertile women, which suggest that systemic antioxidant defense mechanisms are consumed in infertile women. This decreasing in TAC levels has been an indicator to reveal that there was not maturation in follicles thus no growing of good oocytes (Revelli et al., 2009). SOD is the enzyme that reacts 
with superoxide anion radicals to form oxygen and $\mathrm{H}_{2} \mathrm{O}_{2}$, its decline has been shown that women with infertility have insufficient antioxidant defense, this result was in accorded with several studies like the study of Szczepanska et al. (2003) that revealed low TAC and significantly reduced SOD levels in infertile women. This reduction in TAC may imply elevated ROS and increased ROS levels imply exhausted antioxidant defense, leads to its inability to scavenge ROS and neutralize their toxic effects (Nsonwu-Anyanwu et al., 2015). MDA represents the end product of polyunsaturated fatty acid oxygenation, is commonly used as the lipid peroxidation level marker and the presence of oxidative stress (Grotto et al., 2009). In our study MDA increasing may be explained by the increased ROS production as a result of higher lipid peroxidation, also according to previous studies there is a direct relation between increased MDA and decreased TAC (Farzadi et al., 2013).

When we examined the impact of age on antioxidants levels, we found nonsignificant variation in TAC, SOD, MDA and GSH between the three age groups, whereas there was slightly decreased in antioxidants such as TAC, SOD and GSH levels with aging and increased in MDA levels. While catalase activity showed significant reduction in age group 3 comparing with the others, this result in accorded with the study of Appasamy et al. (2008) that found there was no significant relationship between age of the woman and plasma TAC and the study of Hussain et al. (2013) that was observed a negative impact of age on catalase values in infertile women which categorized into three age groups. The present results confirmed that magnesium concentration in serum was significantly decreased in infertile women as compared with fertile group; on the other hand, magnesium concentration expressed a significant elevation in the age group 3 . This result corresponds to study of Howard et al. (1994) that demonstrated magnesium role in enhancing fertility and increasing pregnancy rate in patients with 
unexplained infertility and low magnesium levels. The significant decreased magnesium concentration in the current study may participate in infertility because magnesium deficiency associates with variable complications of female reproductive system. Our results revealed that serum zinc concentration was significantly reduced in infertile group in comparison with the fertile group, this showed that zinc deficiency can play a negative significant role in female infertility and this was related to other previous studies demonstrated the same like the founding of Ceko et al. (2016), Zinc deficiency causes impaired synthesis and secretion of LH and FSH which leads to disruption of the pituitary-ovarian axis function and estrous cycle (Bedwal and Bahuguna, 1994).the data showed a significant elevation in the level of serum IL-1 $\beta$ between infertile and fertile groups. This result was not corresponded with the study of Kalu et al. (2007) on infertile women, who were found that serum level of IL-1 $\beta$ was not significantly different in the patients and controls. Indeed, IL-1 $\beta$ levels are reported to be decreased in endometrium of women with recurrent miscarriage, suggesting that a fail in activating the pathways downstream of IL-1 $\beta$ may contribute to pregnancy failure (Rossi et al., 2005). Also it was seen that any increasing of follicular fluid IL-1 $\beta$ level was associated with fertilization. Previous studies suggested that ability to generate a healthy fetus and successful in vivo fertilization occur in the oocytes in follicles with lower concentration of IL-1 $\beta$ in follicular fluid (Revelli et al., 2009). reason may due to IL-1 $\beta$ role in suppressing estradiol and progesterone release from granulosa and luteal cells (Mahdi, 2011).

\section{References}

Calogero, A. E.; Nicoletti, F.; Palumbo, M. A.; Burrello, N.; Di Mauro, M.; Lunetta, M.; Bendtzen, K. and Cianci, A. (1998). Macrophage-derived cytokines in the follicular fluids of women with infertility due to 
immunological causes. Elevated levels of interleukin 6 and low levels of granulocyte-macrophage colony-stimulating factor. Cytokine,10(10): 814-818. Bedwal, s. and Bahuguna, A. (1994). Zinc, Copper and Selenium in reproduction. Experientia 50(7):626-640

Rossi, M.; Sharkey, A. M.; Vigano, P., Fiore, G.; Furlong, R.; Florio, P.; Ambrosini, G.; Smith, S. K. and Petraglia, F. (2005). Identification of genes regulated by interleukin-1b in human endometrial stromal cells. Reproduction, 130:721-729

Moron, M. S.; Dipierre, J. W. and Mannervik, B. (1979). Levels of glutathione reductase and glutathione-S-transferase activities in rat lung and liver. Biochem Biophy Acta 582: 67-68.

Howard, J. M.; Davies, S and Hunnisett, A. (1994). Red cell magnesium and glutathione peroxidase in infertile women -effects of oral supplementation with magnesium and selenium. Magnesium Research, 7(1): 49-57

Ceko, M. J.; O’Leary, S.; Harris, H. H.; Hummitzsch, K. and Rodgers, R. J. (2016). Trace Elements in Ovaries: Measurement and Physiology. Biology of Reproduction, 94(4):86, 1-14

Hussain, M. K.; Mohammed, H. J.; Al- Ghazali, B. S. and Abdul Hasan, M. T. (2013). Oxidative Stress in Primary Infertility of Women. Global Journal of Medical Research, 13(2) 1:8 pages

Appasamy, M.; Jauniaux, E. Serhal, P.; Al-Qahtani, A.; Groome, N. P. and Muttukrishna, S. (2008). Evaluation of the relationship between follicular fluid oxidative stress, ovarian hormones, and response to gonadotropin stimulation. Fertility and Sterility, 89(4): 912-921

Nsonwu-Anyanwu, A. C.; Charles-Davies, M. A.; Taiwo, V. O.; Li, B.; Oni, A. A. and Bello, F. A. (2015). Female Reproductive Hormones and Biomarkers of Oxidative Stress in Genital Chlamydia Infection in Tubal Factor Infertility. J. Reprod. Infertil., 16(2):82-89

Grotto, D.; SantaMaria, L.; Valentini, J.; Paniz, C.; Schmitt, G. and Garcia, S. C. (2009). Importance of the lipid peroxidation biomarkers and methodological aspects for malondialdehyde quantification. Química Nova Journal, 32: 169174

Szczepanska, M.; Kozlik, J.; Skrzypczak, J. and Mikolajczyk, M. (2003). Oxidative stress may be a piece in the endometriosis puzzle. Fertility and Sterility, 79: 
$1288-1293$

Domingues, T. S.; Rocha, A. M. and Serafini, P. C. (2010). Tests for ovarian reserve. Current Opinion in Obstetrics and Gynecology, 22: 271-276.

Farzadi, L.; Khaki, A.; Ghasemzadeh, A.; Bahrami, A. Z.; Khan ahamadi, S. and Ashteani, H. A. (2013). Effect of Allium Cepa seeds Ethanolic Extract, on Serum Total Antioxidant in Experimental induced Poly cystic ovarian (PCO) rats. Life Science Journal 10(4): 97-102.

Gupta, S.; Malhotra, N.; Sharma, D.; Chandra, A. and Ashok, A. (2009). Oxidative Stress and its Role in Female Infertility and Assisted Reproduction: Clinical Implications. International Journal of Fertility and Sterility 2(4): 147-164.

Boehm, U.; Bouloux, P. M.; Dattani, M. T.; Roux, N.; Dodé, C.; Dunkel, L.; et al. (2015). Expert consensus document: European Consensus Statement on congenital hypogonadotropic hypogonadism-pathogenesis, diagnosis and treatment. Nat. Rev. Endocrinol. 11:547-564.

Revelli, A.; Piane, L. D.; Casano, S.; Molinari, E.; Massobrio, M. and Rinaudo, P. (2009). Follicular fluid content and oocyte quality: from single biochemical markers to metabolomics. Reproductive Biology and Endocrinology, 7:40

D'Hooghe, T.M. and Debrock, S. (2002). Endometriosis, retrograde menstruation and peritoneal inflammation in women and in baboons. Human Reproduction Update, 8:84-8

DeRidder, G. and Gossen, D. (1988). Magnesium in pregnancy - relationship to prophylaxis and therapy of early contractionsand threatening premature births. Magnesium Research, 1:247

Franks, S.; Stark, J. and Hardy, K. (2008). Follicle dynamics and anovulation in polycystic ovary syndrome. Human Reproductive Update, 14(4): 367

Fukai, F. and Murayama, A. (1984). Association and dissociation of oestrogen receptor-binding factors is regulated by $\mathrm{Mg}^{2+}$. J. Biochem., 95: 1227-1230

Hussain, M. K.; Mohammed, H. J.; Al- Ghazali, B. S. and Abdul Hasan, M. T. (2013). Oxidative Stress in Primary Infertility of Women. Global Journal of Medical Research,13(2) 1:8 pages

Jetawattana, S. (2005). Malondialdehyde (MDA), a lipid oxidation product Department of Radiation Oncology, Free Radical and Radiation Biology, The University of Iowa, 77: 222

Jungheim, E. S. (2015). Obesity and Fertility: A Practical Guide for Clinicians. 
Springer Science and Business Media, New York, pp:153-154

Lambrinoudaki I V, Augoulea A, Christodoulakos G E, Economou E V, Kaparos G, Kontoravdis A, Papadias C, Creatsas G (2009). Measurable serum markers of oxidative stress response in women with endometriosis. Fertil Steril 91:4650.

Liu RH, Li H, Jiao L-H, Wang X-N, Wang Hong, Wang W-H (2002). Extracellular and intracellular factors affecting nuclear and cytoplasmic maturation of porcine oocytes collected from different sizes of follicles.Zygote Cambridge University Press 10(3): 253-260.

Mahdi, B. M. (2011). Role of some cytokines on reproduction. Middle East Fertility Society Journal, 16: 220-223

Niedernhofer, L. J.; Daniels, J. S.; Rouzer, C. A.; Greene, R. E. and Marnett, L. J. (2008). Malondialdehyde, a Product of Lipid Peroxidation, Is Mutagenic in Human Cells. The Journal of Biological Chemistry, 278: 31426-31433.

Noori, S. H. (2012). Significance of Anti-Mullerian Hormone in Quantitative and Qualitative Aspects of Assisted Reproduction Technology. Academic Dissertation, Faculty of Medicine Science, University of Sulaimani, Kurdistan, Iraq.

Olooto, W. E.; Adeleye, A. O.; Amballi, A. A. and Mosuro, A. O. $\left(2012^{\text {b }}\right)$. Pattern of Reproductive Hormones (Follicle Stimulating Hormone, Luteinizing Hormone, Estradiol, Progesterone, and Prolactin Levels in Infertile Women in Sagamu South Western Nigeria. Der. Pharmacia Letter, 4(2): 549-553

Olooto, W. E.; Amballi, A. A. and Banjo, T. A. (2012 $)$. A review of female infertility; important etiological factors and management. J. Microbiol. Biotech. Res., 2(3):379-385

Rajeswari, S. and Swaminathan, S. (2015). Role of Zinc and Copper in Infertility. Int. J. of Multidisciplinary and Current research 3: 607-612

Saleh, B. O.; Ibraheem, W. F. and Ameen, N. S. (2015). The role of anti-Mullerian hormone and inhibin B in the assessment of metformin therapy in women with polycystic ovarian syndrome. Saudi. Med. J., 36(5): 562-567

Vander, A. J.; Luciano, D. and Sherman, J. (2001). Human Physiology: The Mechanisms of Body Function, $8^{\text {th }}$ Edition, McGraw-Hill Companies.

Zheng, H.; McConnell, D.; Nan, B.; Harlow, S. and Randolph, J. F. (2008). New Hormone Data Can Predict Menopause Within A Year. EurekAlert. Available from: http://www.eurekalert.org/pub_releases 2008-10/uomnhd102708. 